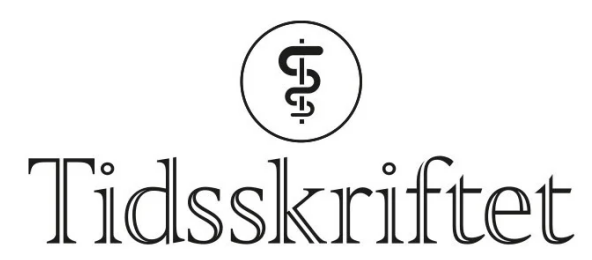

DEN NORSKE LEGEFORENING

\title{
Knuter i tyreoidea - utredning og oppfølging
}

\author{
KLINISK OVERSIKT
}

\section{ÅSE TANGERUD}

aastan@ous-hf.no

Avdeling for radiologi og nukleærmedisin

Oslo universitetssykehus, Radiumhospitalet

Hun har bidratt med idé til artikkelen og utarbeiding, revisjon og godkjenning av manus.

Åse Tangerud er spesialist i radiologi og overlege.

Forfatteren har fylt ut ICMJE-skjemaet og oppgir ingen interessekonflikter.

\section{EVA SIGSTAD}

Avdeling for patologi

Klinikk for laboratoriemedisin

Oslo universitetssykehus, Radiumhospitalet

Hun har bidratt med idé til artikkelen og utarbeiding, revisjon og godkjenning av manus. Eva Sigstad er ph.d., spesialist i patologi og overlege.

Forfatteren har fylt ut ICMJE-skjemaet og oppgir ingen interessekonflikter.

\section{KRISTIN HOLGERSEN FAGERLID}

Avdeling for radiologi og nukleærmedisin Oslo universitetssykehus, Radiumhospitalet Hun har bidratt med idé til artikkelen og utarbeiding, revisjon og godkjenning av manus. Kristin Holgersen Fagerlid er spesialist i radiologi og overlege.

Forfatteren har fylt ut ICMJE-skjemaet og oppgir ingen interessekonflikter.

\section{TROND HARDER PAULSEN}

Seksjon for bryst- og endokrinkirurgi

Oslo universitetssykehus, Aker sykehus

Han har bidratt med idé til artikkelen og utarbeiding, revisjon og godkjenning av manus. Trond Harder Paulsen er spesialist i generell kirurgi og i endokrinkirurgi og overlege. Forfatteren har fylt ut ICMJE-skjemaet og oppgir ingen interessekonflikter.

\section{INGRID NORHEIM}

Tyreoideaseksjonen

Oslo universitetssykehus, Aker sykehus

Hun har bidratt med idé til artikkelen og utarbeiding, revisjon og godkjenning av manus. Ingrid Norheim er dr.med., spesialist i endokrinologi og seksjonsoverlege. Forfatteren har fylt ut ICMJE-skjemaet og oppgir ingen interessekonflikter. 
Knuter i tyreoidea er vanlig. Ved økt bruk av

bildediagnostikk påvises flere knuter som tilfeldige funn. De aller fleste er benigne og trenger ingen behandling. Systematisk ultralydundersøkelse utført av lege med god kompetanse, eventuelt kombinert med cytologisk prøvetaking, vil i stor grad kunne avklare hvilke knuter som krever oppfølging.

Knuter i tyreoidea er en vanlig klinisk problemstilling. Epidemiologiske studier har vist at prevalensen av palpable knuter hos voksne er omkring $5 \%$ hos kvinner og $1 \%$ hos menn (1). Undersøkelser med høyoppløselig ultralyd kan avdekke knuter i tyreoidea hos 19-68 \% av tilfeldig undersøkte personer ( $\underline{1})$.

For klinikere og radiologer uten erfaring innen tyreoideadiagnostikk kan det være utfordrende å utrede og vurdere knuter i tyreoidea. Med bakgrunn i Nasjonalt handlingsprogram med retningslinjer for utredning, behandling og oppfølgning av kreft $i$ skjoldbruskkjertelen som ble utgitt i 2017 (2) , nyere internasjonal litteratur og egne erfaringer vil vi anbefale en fremgangsmåte for målrettet utredning av knuter i tyreoidea.

De fleste knuter i tyreoidea er benigne (87-95\%) (3). Målet med utredningen er å identifisere den lille gruppen pasienter med kreft i tyreoidea, og samtidig unngå unødvendige undersøkelser av pasienter med godartede knuter. God anamnese og palpasjon utført av undersøkende lege er avgjørende i den kliniske vurderingen.

Alle henvisninger til bildediagnostikk skal inneholde detaljer om sykehistorien og den kliniske undersøkelsen (ramme 1). I de sjeldne tilfellene der mistanken om kreft er stor, bør pasienten henvises direkte til pakkeforløp for kreft i spesialisthelsetjenesten (ramme 2).

Ramme 1 Kliniske opplysninger som grunnlag for henvisning til ultralydundersøkelse av hals.

\section{Anamnese og klinisk vurdering av kreftrisiko}

- Tidligere strålebehandling av hodet eller halsen

- Familiær disposisjon for tyreoideakreft

- Alder under 18 år og over 70 år (spesielt hos menn)

- Rask vekst av en knute

Klinisk undersøkelse med palpasjonsfunn

- Hard konsistens, fiksert lesjon, palpable lymfeknuter (se alarmsymptomer i ramme 2)

- Persisterende dysfoni (hes stemme), dysfagi eller dyspnoe (se alarmsymptomer i ramme 2)

\section{Blodprøver}

- TSH, fritt tyroksin ( $\mathrm{fT}_{4}$ ), fritt trijodtyronin ( $\mathrm{fT}_{3}$ ), antistoff mot tyreoideaperoksidase (anti-TPO) og s-kalsium (ev. kalsitonin)

Ramme 2 Symptomer og funn som krever rask utredning og henvisning til pakkeforløp (2).

\section{Alarmsymptomer}


- Palpabel tumor og minst ett av følgende:

- Fiksert tumor

- Rask vekst av tumor

- Nyoppstått heshet

- Blodig hoste

- Nyoppståtte svelge- og pustevansker

- Nyoppståtte smerter

\title{
Barn (under 18 år) med knute i tyreoidea
}

\author{
Radiologiske funn, molekylære funn eller celleforandringer ved \\ finnålscytologi \\ - Malignitetssuspekte funn på CT- eller ultralydundersøkelse \\ - Bethesda-gruppe 5 og 6 \\ - BRAF-mutasjon
}

De fleste pasienter med klinisk eller radiologisk påvist knute i tyreoidea blir henvist til målrettet ultralydundersøkelse på sykehus eller røntgeninstitutt. Avhengig av funnene ved denne undersøkelsen avgjøres det om pasienten er ferdig utredet (benignt radiologisk funn), og pasienten trenger da ikke supplerende undersøkelser eller ultralydkontroll. Henvisning til ny kontroll med ultralyd anbefales kun dersom det tilkommer nye symptomer (ramme 1) eller funn som er alarmerende (ramme 2). Det bør fremkomme klart av ultralydbeskrivelsen hvorvidt det er behov for videre utredning med ultralydveiledet finnålscytologi (FNC). Pasienten bør da henvises til et senter hvor dette kan utføres.

Det er stor variasjon i kompetansen til legene som utfører den initiale ultralydunders $\varnothing$ kelsen. Om utredningen ikke er konklusiv, for eksempel ved suboptimal ultralydvurdering eller manglende mulighet til prøvetaking med finnål, må pasienten undersøkes på ny og eventuelt henvises til et kompetansesenter for tverrfaglig vurdering og behandling. Vi har de siste fem årene registrert en $\emptyset$ kning av henvisninger til tverrfaglig vurdering på rundt $50 \%$ ved vårt kompetansesenter ved Oslo universitetssykehus.

De siste tiårene har antallet krefttilfeller i tyreoidea økt i Norge, og i 2018 var det 408 nye tilfeller (294 kvinner og 114 menn) (4). Mortaliteten ved tyreoideakreft er stabil. Median alder ved diagnose var 54 år i perioden 2014-18, og har vært nærmest uendret fra 1984 (4). $\emptyset \mathrm{kt}$ bruk av bildediagnostikk har bidratt til at flere tilfeller av kreft i tyreoidea oppdages. De fleste kreftknutene er karsinomer med god prognose (5). Metastaser utgjør kun o,2 \% av maligne tumorer i tyreoidea i rutinediagnostikk (5), og blir i all hovedsak avdekket og håndtert i spesialisthelsetjenesten.

Moderne og adekvat ultralyddiagnostikk kan i stor grad skille malignitetssuspekte knuter fra benigne. Sammen med et adekvat cytologisk materiale vil det som regel kunne stilles en diagnose som er så sikker at den kan gi grunnlag for beslutning om videre forløp. Det er viktig at den som utfører ultralydundersøkelsen, har god erfaring og kompetanse i vurdering av knuter i tyreoidea. Økt fokus på opplæring i ultralyddiagnostikk av tyreoidea og etablering av sentre med muligheter for ultralydveiledet finnålspunksjon og eventuelt tilstedeværelse av screener (bioingeniør) eller cytolog under prøvetakingen, vil kunne bidra til at flere pasienter får sine knuter avklart ved første ultralydvurdering. På noen institusjoner, der cytopatologene selv utfører ultralydundersøkelsen og eventuell medfølgende punksjon, oppnås høy treffsikkerhet (므). Dette krever imidlertid en tilstrekkelig bemanning av ultralydkompetente cytopatologer.

Rutinemessig anvendelse av standardiserte maler for besvarelse av ultralydundersøkelse og cytologisk vurdering vil kunne bidra til en sikrere diagnose (7.). En samlet vurdering av kliniske funn, ultralydundersøkelser og cytologisk prøvetaking avgjør det videre forløpet for pasienten. Et godt tverrfaglig samarbeid mellom kliniker, radiolog og patolog er 
avgjørende for å oppnå en mest mulig sikker diagnose, og vil være til stor hjelp for å avklare tilfeller der det er diskrepans mellom kliniske funn og funn ved ultralydundersøkelse eller cytologisk vurdering.

\section{Bildediagnostikk}

Ultralyd er den beste bildemodaliteten til å vurdere og karakterisere knuter i tyreoidea og kan avklare om det er indikasjon for finnålscytologi. Hos pasienter uten risikofaktorer for utvikling av kreft i tyreoidea skal ultralydundersøkelse ikke utføres som screening. Ultralyd anbefales heller ikke rutinemessig ved hypo- eller hypertyreose. Dersom pasienten har palpable knuter, økende knutestruma, forstørrede lymfeknuter på halsen eller klinisk mistanke om malign lesjon, skal ultralydundersøkelse av halsen utføres. Ved plager og ubehag over kjertelen må klinikeren vurdere om pasienten skal henvises til ultralyd.

En normal tyreoideakjertel er velavgrenset med homogen ekkostruktur ved ultralyd. Hos voksne er lengden av hver lapp vanligvis $4-6 \mathrm{~cm}$ og bredden/tykkelsen opptil $2 \mathrm{~cm}$.

Normalt tyreoideavolum hos kvinner er 10-15 ml og hos menn 12-18 ml (모). Ved vurdering av en tyreoideaknute skal størrelse og lokalisasjon beskrives. Knutens ekkogenisitet, form, avgrensning, forkalkninger og vaskularisering samt eventuelle tegn til vekst utenfor tyreoidea bør nøye beskrives. Hvis pasienten har flere knuter, må hver av disse vurderes.

En typisk benign tyreoideaknute har et cystisk eller spongiøst (svampaktig) preg, er velavgrenset og har oval form (figur 1a). Hvis pasienten har flere ensartede og velavgrensede knuter i en forstørret kjertel, er disse som regel benigne og undersøkes ikke nærmere cytologisk. Kontroll med ultralydundersøkelse utføres kun dersom det tilkommer symptomer eller funn som er alarmerende (ramme 2).

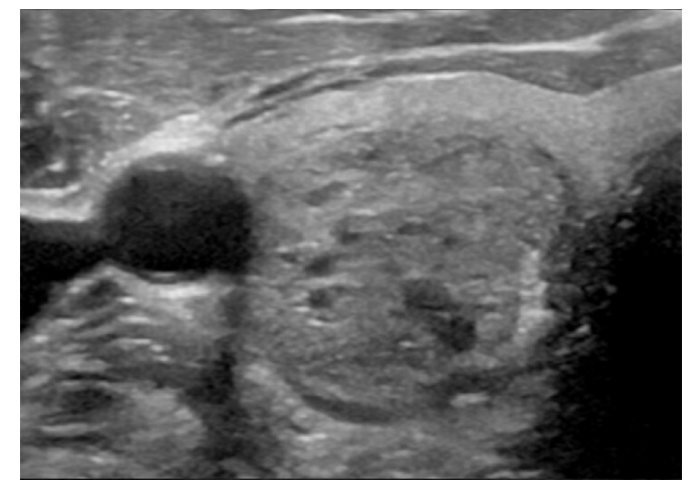

a

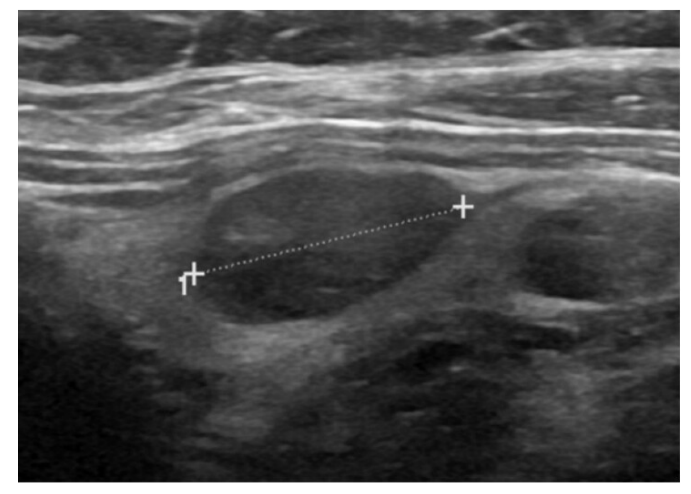

C

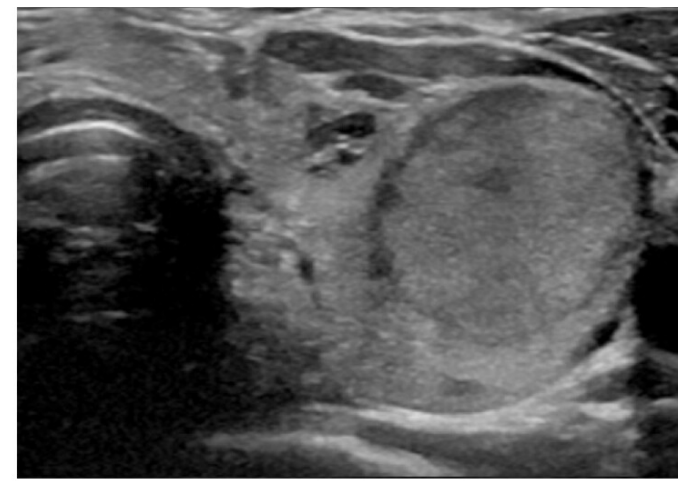

b

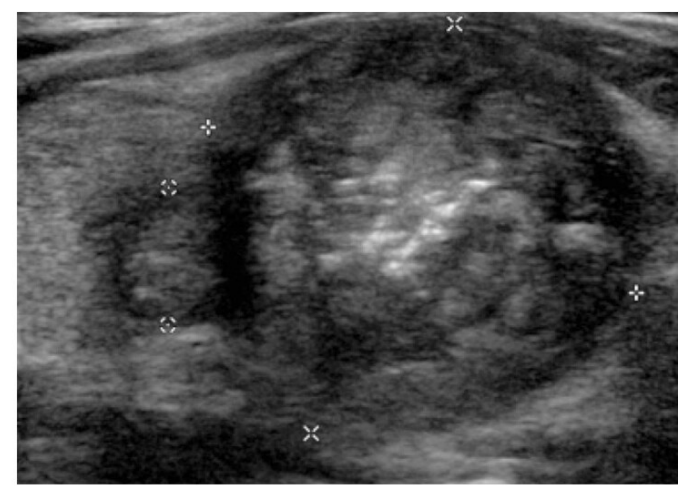

d

Figur 1 Typiske ultralydfunn ved ulike klassifiseringer av risiko for malignitet i tyreoidea (TIRAD = Thyroid Imaging Reporting and Data System ). a) Knuten er oval, velavgrenset og svampaktig. Den har et benignt preg (TIRAD 2). b) Knuten er oval, velavgrenset og isoekkoisk. Det er lav risiko for kreft (TIRAD 3). c) Knuten er oval, velavgrenset og moderat hypoekkoisk. Det er moderat risiko for kreft (TIRAD 4). d) Knuten er uskarpt avgrenset, 
inneholder mikrokalk og er markert hypoekkoisk perifert. Det er høy risiko for kreft

(TIRAD 5).

Malignitetssuspekte tyreoideaknuter er gjerne solide og lav-/hypoekkogene, har uregelmessig avgrensning og irregulær form og kan inneholde mikroforkalkninger (figur 1d). Disse knutene må undersøkes videre med finnålscytologi.

Ved mistanke om kreft i tyreoidea skal hele halsen undersøkes med ultralyd for å se om det foreligger lymfeknutemetastaser. En patologisk lymfeknute på halsen kan være første tegn på kreft i tyreoidea (9).

I USA og flere europeiske land brukes rapporteringssystemer (7.), (10-12) med ultralydkriterier for å gradere risikoen for malignitet. Slike systemer sikrer standardiserte ultralydbeskrivelser og kan bedre kommunikasjonen mellom radiolog, cytolog og kliniker. American College of Radiology (ACR) bruker Thyroid Imaging Reporting and Data System (TIRAD) som klassifikasjonssystem etter inspirasjon fra Breast Imaging and Reporting Data System (BIRAD). Europeiske retningslinjer anbefaler en variant av dette: EU-TIRAD (1ㅡ). EUTIRAD klassifiserer hver knute i en bestemt risikogruppe ut fra ultralydkriterier. ACRTIRAD samsvarer i hovedsak med EU-TIRAD $(7, \underline{10})$ men ACR-TIRAD beregner risiko ved å summere flere ultralydkriterier (므, 13), . I hver risikogruppe blir behovet for finnålscytologi angitt ut fra knutens størrelse (tabell 1).

\section{Tabell 1}

Kriterier for klassifisering av risiko for malignitet i tyreoidea basert på ultralydfunn. Tabellen viser klassifisering benyttet av American College of Radiology (ACR) og klassifisering benyttet av EU. Det amerikanske klassifiseringssystemet er basert på poeng ved ultralydfunn av knutenes sammensetning, ekkogenisitet, form, avgrensning og ekkogene foci. I det europeiske systemet klassifiseres funnene som angitt i tabellen (10, 12, 13). TIRAD = Thyroid Imaging Reporting and Data System. FNC = finnålscytologi.

\begin{tabular}{|c|c|c|c|c|c|}
\hline \multicolumn{2}{|c|}{ Kategori Vurdering } & ACR-TIRAD & \multicolumn{2}{|c|}{$\begin{array}{l}\text { ACR-TIRAD EU-TIRAD } \\
\text { Ultralydpoeng }\end{array}$} & \multirow{2}{*}{$\begin{array}{l}\text { EU-TIRAD } \\
\text { Ultralydfunn } \\
\text { Ingen knuter }\end{array}$} \\
\hline TIRAD 1 & $\begin{array}{l}\text { Normal, } \\
\text { benign }\end{array}$ & $\begin{array}{l}\text { Ingen FNC / } \\
\text { ingen } \\
\text { kontroll }\end{array}$ & 0 & $\begin{array}{l}\text { Ingen FNC / } \\
\text { ingen } \\
\text { kontroll }\end{array}$ & \\
\hline TIRAD 2 & Ikke suspekt & $\begin{array}{l}\text { Ingen FNC / } \\
\text { ingen } \\
\text { kontroll }\end{array}$ & 2 & $\begin{array}{l}\text { Ingen FNC / } \\
\text { ingen } \\
\text { kontroll }\end{array}$ & $\begin{array}{l}\text { Cyste, spongiøs } \\
\text { og svampaktig } \\
\text { (blandet solid og } \\
\text { cystisk) }\end{array}$ \\
\hline TIRAD 3 & Lav risiko & $\begin{array}{l}\text { FNC av knute } \\
\geq 2,5 \mathrm{~cm} \\
\text { Kontroll } \geq \\
1,5 \mathrm{~cm}\end{array}$ & 3 & $\begin{array}{l}\text { FNC av knute } \\
>2 \mathrm{~cm}\end{array}$ & $\begin{array}{l}\text { Oval } \\
\text { Velavgrenset } \\
\text { Iso-/hypoekkoisk } \\
\text { Ingen } \\
\text { høyrisikotegn }\end{array}$ \\
\hline TIRAD 4 & $\begin{array}{l}\text { Moderat } \\
\text { suspekt / } \\
\text { intermediær } \\
\text { risiko }\end{array}$ & $\begin{array}{l}\text { FNC av knute } \\
\geq 1,5 \mathrm{~cm} \\
\text { Kontroll } \geq \\
1 \mathrm{~cm}\end{array}$ & $4-5$ & $\begin{array}{l}\text { FNC av knute } \\
>1,5 \mathrm{~cm}\end{array}$ & $\begin{array}{l}\text { Oval } \\
\text { Velavgrenset } \\
\text { Middels } \\
\text { hypoekkoisk } \\
\text { Ingen } \\
\text { høyrisikotegn }\end{array}$ \\
\hline
\end{tabular}




\begin{tabular}{|c|c|c|c|c|}
\hline Kategori Vurdering & ACR-TIRAD & $\begin{array}{l}\text { ACR-TIRAD } \\
\text { Ultralydpoeng }\end{array}$ & EU-TIRAD & $\begin{array}{l}\text { EU-TIRAD } \\
\text { Ultralydfunn }\end{array}$ \\
\hline TIRAD 5 Høy risiko & $\begin{array}{l}\text { FNC av knute } \\
\geq 1 \mathrm{~cm} \\
\text { Kontroll } \geq \\
0,5 \mathrm{~cm}\end{array}$ & 7 og flere & $\begin{array}{l}\text { FNC av knute } \\
>1 \mathrm{~cm} \\
\text { Kontroll/FNC } \\
<1 \mathrm{~cm}\end{array}$ & $\begin{array}{l}\text { Minst ett av } \\
\text { følgende } \\
\text { høyrisikotegn: } \\
\text { Irregulær form } \\
\text { Irregulær } \\
\text { avgrensning } \\
\text { Mikrokalk } \\
\text { Markert } \\
\text { hypoekkoisk og } \\
\text { solid }\end{array}$ \\
\hline
\end{tabular}

Den enkelte knutes vaskularisering er ikke med i TIRAD-kriteriene, men kan gi viktig tilleggsinformasjon.

TIRAD er et oversiktlig rapporteringssystem som kan heve kvaliteten på ultralydundersøkelsene (tabell 1, figur 1). Systemet kan også bidra til å redusere overdiagnostikk. Vi vil foreslå at EU-TIRAD brukes som standard ved besvarelse av ultralydundersøkelse av tyreoidea. ACR-TIRAD er imidlertid likeverdig, og finnes også som en enkel nettbasert kalkulator (15). Det bør komme frem i svaret hvilket system som er benyttet.

Scintigrafi har ingen plass i diagnostikk av knuter i tyreoidea. Det utføres bare om konsentrasjonen av s-TSH (tyreoideastimulerende hormon) er lav, for å avdekke (eventuelt utelukke) et hyperfungerende adenom (므).

American College of Radiology har laget retningslinjer (såkalte white paper guidelines)(约) for knuter som blir påvist tilfeldig ved CT- og MR-undersøkelser. De anbefaler videre utredning med ultralyd av knuter større enn $15 \mathrm{~mm}$ hos pasienter over 35 år og knuter større enn $10 \mathrm{~mm}$ hos pasienter under 35 år (므). De norske retningslinjene følger disse

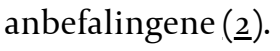

PET-CT benyttes rutinemessig ved utredning av flere typer kreft. Et tilfeldig funn med $ø \mathrm{kt}$ opptak av FDG (fluor-18-merket deoksyglukose) i tyreoidea er assosiert med malignitet hos rundt $30 \%(\underline{16})$. Disse pasientene skal derfor henvises til ultralyd med finnålscytologi $(\underline{2}, \underline{16})$.

\section{Ultralydveiledet finnålscytologisk prøvetaking}

Det er påvist høyere prosentandel diagnostisk materiale ved ultralydveiledet cytologisk undersøkelse sammenliknet med palpasjonsveiledet cytologisk undersøkelse (17.). Finnålscytologi skal derfor utføres med ultralydveiledning. Det anbefales å bruke tynne nåler ( $25 \mathrm{G}$ eller $27 \mathrm{G}$, hhv. o,46 mm og 0,36 mm i diameter) uten aspirasjon. Unntaksvis kan en 23G-nål (o,6o mm i diameter) benyttes ved cystiske lesjoner. Ultralydveiledet finnålscytologi sikrer at det blir stukket i «riktig» knute/lesjon, og i riktig område i knuten.

\section{Cytopatologisk vurdering av materiale fra tyreoidea}

Henvisning til cytologisk undersøkelse bør inneholde informasjon om kliniske funn og funn ved ultralydundersøkelsen. Dette er avgjørende for at patologen skal kunne gi en god vurdering av preparatet, og for å unngå feiltolkning.

Cytologisk vurdering av finnålsutstryk fra tyreoidealesjoner følger den internasjonale Bethesda-klassifikasjonen (묘). Innføringen av denne klassifikasjonen har bidratt til at diagnosene avgitt av patologene er mer enhetlige, konsekvente og enklere for klinikerne å 
forholde seg til. Klassifikasjonssystemet ble introdusert internasjonalt i 2010, og ble oppdatert og revidert i 2017. Bethesda-klassifikasjonen på cytologiske preparater fra tyreoidea ble implementert i Norge i 2013-14. Klassifikasjonen er inndelt i seks grupper. Hver gruppe har en betegnelse og er nummerert fra 1 til 6, der 1 er uegnet materiale, 2 er sikkert benignt materiale, 3 er uavklart materiale, 4 er neoplastisk materiale, 5 er malignitetssuspekt materiale, og 6 er sikkert malignt materiale. Det kan være små nyanser mellom ulike laboratorier med hensyn til klassifiseringen av cytologimaterialet i de seks gruppene, men klassifikasjonssystemet synes å være godt etablert i miljøene som utreder lesjoner i tyreoidea. Bethesda-klassifikasjonen beskriver også risikoen for malignitet for hver av de seks gruppene og gir konkrete anbefalinger for videre håndtering. Dette er nyttig for legene som er involvert i utredningen. I Norge er det erfaringsmessig for mange ikke-vurderbare preparater (Bethesda-gruppe 1). Erfarne leger bør utføre den ultralydveiledete prøvetakingen for å øke andelen prøver med diagnostisk materiale (Bethesda-gruppe 2-6) (묘). Uavhengig av hvem som punkterer, vil det være en fordel at en screener eller cytolog er til stede når finnålspunksjonen utføres, slik at kvaliteten på materialet kan vurderes umiddelbart, såkalt rapid on-site evaluation (ROSE) (199.). Vår erfaring er at et nært samarbeid mellom legen som utfører undersøkelsen (radiolog/kliniker), og screener/cytolog hever kvaliteten på utredningen.

\section{Oppsummering}

Knuter i tyreoidea er vanlig, og de aller fleste er benigne. Ultralyd er den beste bildemodaliteten til å vurdere knuter i tyreoidea. For å heve kvaliteten på ultralydundersøkelsene og for å unngå overdiagnostikk anbefaler vi målrettet opplæring av alle som utfører ultralyd av tyreoidea. Legen som utfører ultralydundersøkelsen, bør bruke et standardisert rapporteringssystem (TIRAD). Finnålscytologi bør utføres med ultralydveiledning. Tilstedeværende screener eller cytolog vil kunne bidra til å sikre prøvekvaliteten. Moderne utredning og behandling av knuter i tyreoidea er avhengig av tett samarbeid mellom kliniker, radiolog og patolog.

Artikkelen er fagfellevurdert.

LITTERATUR

1. Cooper DS, Doherty GM, Haugen BR et al. Revised American Thyroid Association management guidelines for patients with thyroid nodules and differentiated thyroid cancer. Thyroid 2009; 19:1167214. [PubMed][CrossRef]

2. Helsedirektoratet. Thyreoideakreft (skjoldbruskkjertelkreft)- handlingsprogram. https://www.helsedirektoratet.no/retningslinjer/thyroideakreft-skjoldbruskkjertelkrefthandlingsprogram Lest 20.5.2020.

3. Russ G, Leboulleux S, Leenhardt L et al. Thyroid incidentalomas: epidemiology, risk stratification with ultrasound and workup. Eur Thyroid J 2014;3:154-63. [PubMed][CrossRef]

4. Cancer in Norway. 2018. Oslo: Kreftregisteret, 2019.

https://www.kreftregisteret.no/Generelt/Rapporter/Cancer-in-Norway/cancer-in-norway-2018/ Lest 20.5.2020.

5. Lloyd RV, Osamura RY, Klöppel G et al. WHO classification of tumours of endocrine organs. Lyon: International agency for research on cancer (IARC), 2017.

6. Sauer T, Doughty RW, Orzsagh V et al. The cytopathologist in the hospital - Based Fnac clinic: US image guidance is our new tool to an even better Fnac practice. Mathews Journal of Cytology and Histology 2018; 2: 1-10.

7. Tessler FN, Middleton WD, Grant EG et al. ACR thyroid imaging, reporting and data system (TIRADS): white paper of the ACR TI-RADS committee. J Am Coll Radiol 2017; 14: 587-95. [PubMed] [CrossRef]

8. Dighe M, Barr R, Bojunga J et al. Thyroid ultrasound: state of the art part 1-thyroid ultrasound reporting and diffuse thyroid diseases. Med Ultrason 2017; 19: 79-93. [PubMed][CrossRef] 
9. Coleman SC, Smith JC, Burkey BB et al. Long-standing lateral neck mass as the initial manifestation of well-differentiated thyroid carcinoma. Laryngoscope 2000; 110: 204-9. [PubMed][CrossRef]

10. Grant EG, Tessler FN, Hoang JK et al. Thyroid ultrasound reporting lexicon: white paper of the ACR thyroid imaging, reporting and data system (TIRADS) committee. J Am Coll Radiol 2015; 12: 1272-9. [PubMed][CrossRef]

11. Middleton WD, Teefey SA, Reading CC et al. Multiinstitutional analysis of thyroid nodule risk stratification using the American College of Radiology Thyroid Imaging Reporting and Data System. AJR Am J Roentgenol 2017; 208: 1331-41. [PubMed][CrossRef]

12. Russ G, Bonnema SJ, Erdogan MF et al. European Thyroid Association guidelines for ultrasound malignancy risk stratification of thyroid nodules in adults: the EU-TIRADS. Eur Thyroid J 2017; 6: 22537. [PubMed][CrossRef]

13. Diaz F, Garcia Duitama I, Radosevic A et al. ACR-TIRADS and EU-TIRADS, are they so different? European Congress of Radiology 2019. doi:10.26044/ecr2019/C-2490.

14. Fish SA. ACR TIRADS is best to decrease the number of thyroid biopsies and maintain accuracy. Clin Thyroidol 2019; 31:113-6. [CrossRef]

15. ACR TIRADS calculator. http://tiradscalculator.com/ Lest 20.5.2015.

16. Hoang JK, Langer JE, Middleton WD et al. Managing incidental thyroid nodules detected on imaging: white paper of the ACR Incidental Thyroid Findings Committee. J Am Coll Radiol 2015; 12: 143-50. [PubMed][CrossRef]

17. Can AS, Peker K. Comparison of palpation-versus ultrasound-guided fine-needle aspiration biopsies in the evaluation of thyroid nodules. BMC Res Notes 2008; 1: 12. [PubMed][CrossRef]

18. Cibas ES, Ali SZ. The 2017 Bethesda system for reporting thyroid cytopathology. Thyroid 2017; 27: 1341-6. [PubMed][CrossRef]

19. Jiang D, Zang Y, Jiang D et al. Value of rapid on-site evaluation for ultrasound-guided thyroid fine needle aspiration. J Int Med Res 2019; 47: 626-34. [PubMed][CrossRef]

Publisert: 3. september 2020. Tidsskr Nor Legeforen. DOI: 10.4045/tidsskr.20.0186

Mottatt 2.3.2020, første revisjon innsendt 12.5.2020, godkjent 15.6.2020.

Publisert under åpen tilgang CC BY-ND. Lastet ned fra tidsskriftet.no 26. april 2023. 